\title{
An ultra sensitive DNA detection by using gold nanoparticle multilayer in nano-gap electrodes
}

\author{
Chien-Ying Tsai ${ }^{\mathrm{a}}$, Tien-Li Chang ${ }^{\mathrm{a}}$, Chun-Chi Chen ${ }^{\mathrm{b}}$, \\ Fu-Hsiang Ko ${ }^{b}$, Ping-Hei Chen ${ }^{\mathrm{a}, *}$ \\ a Department of Mechanical Engineering, National Taiwan University, No. 1, Roosevelt Road Sec. 4, Taipei 10617, Taiwan \\ b National Nano Device Laboratories, Hsinchu 300, Taiwan
}

Available online 11 January 2005

\begin{abstract}
This paper reports an electrical DNA detection method that detects target DNA at concentrations as low as $1 \mathrm{fM}$ by using self-assembly multilayer gold nanoparticle structure between nano-gap electrodes. The distance of the gap between the electrodes is $300 \mathrm{~nm}$ and the height of the electrodes is $65 \mathrm{~nm}$. A multilayer gold nanoparticle structure can be built on thin film of $\mathrm{SiO}_{2}$ silicon wafer. Bifunctional organic molecules are used to build up gold nanoparticle monolayer on the wafer substrate. After hybridization among target DNA, 5'-end thiol-modified probe DNA and $3^{\prime}$-end thiol-modified capture DNA; a second layer of gold nanoparticle is built up through a self-assembly process between gold nanoparticles and thiol-modified end of probe DNA. When the applied voltage is the same, electrical current through multilayer gold nanoparticle structure is much greater than that through monolayered gold nanoparticle structure. Therefore, target DNA in sample solution can be detected through a significant degradation in electrical resistance from monolayered gold nanoparticle to multilayer gold nanoparticle structures. The concentration of target DNA in tested sample solutions ranges from $1 \mathrm{fM}$ to $100 \mathrm{pM}$. The linear $I-V$ curves of multilayer gold nanoparticle structures indicate the device proposed in this study can detect target DNA concentrations as low as $1 \mathrm{fM}$. Additional approaches are also suggested in this study to improve the sensitivity in DNA detection by using $I-V$ measurements through multilayer gold nanoparticle structures.
\end{abstract}

(C) 2005 Elsevier B.V. All rights reserved.

Keywords: DNA detection; Self-assembly; Gold nanoparticles; Bifunctional organic molecules; Monolayer; Multilayer

\footnotetext{
${ }^{*}$ Corresponding author. Tel./fax: +88622367 0781; fax: +88 6223631755.

E-mail address: phchen@ntu.edu.tw (P.-H. Chen).
}

\section{Introduction}

In recent years, many approaches have been developed to detect DNA for diagnosis of genetic diseases. The success of these approaches heavily 
relies on the integration of interdisciplinary knowledge of molecular biology, chemistry and physics. Among these detection approaches, gold nanoparticles (AuNPs) that serve as tag material in both optical and electrical approaches reveal high sensitivity and selectivity [1-6]. In our prior studies $[7,8]$, gold nanoparticles served as tag material for electrical detection of DNA hybridization. First, self-assembly gold nanoparticle monolayer is immobilized on $\mathrm{SiO}_{2}$ surface between nanogap electrodes by using a chemical compound, with 3-Mercaptopropyltrimethoxysilane (MPTMS). Then, gold nanoparticles could be added to the surface of the monolayer through hybridization among thiol-modified capture, thiol-modified probe, and target DNA single strands. A sharp rise in electric current through nanogap electrodes can be observed if additional layer of gold nanoparticles through DNA hybridization is formed on the self-assembly gold nanoparticle monolayer [7]. In addition, the electric conductivity of selfassembly gold nanoparticle multilayer increases with the concentration of target DNA [7-9].

Metallic nanoparticles have been used to establish self-assembly nanostructure of which physical and chemical properties have been investigated in recent years. In particular, gold nanoparticles can be easily prepared and have the characteristic of biocompatibility [10]. Some new devices have been developed for the application of immunoassay by making use of the novel properties of nanostructure that is self-assembled by gold nanoparticles [11]. However, the properties of gold nanostructure can vary significantly with the size of gold nanoparticles and the pitch between gold nanoparticles in the nanostructures [10-13]. A gold-amplified sandwich immunoassay for the detection of human immunoglobulin $G$ has also been developed by Natan and coworkers [13]. The sensitivity of their immunoassay can reach $1 \mathrm{pM}$. They have also conducted a series of studies on the effect of particle size and surface coverage on the detective sensitivity of immunoassay [14,15]. In 2002, Mirkin and his group immobilized AuNPs on the gap surface between two 20-micro-gap electrodes through hybridization among target DNA (tDNA), capture DNA (cDNA), and probe DNA (pDNA)
[16]. However, the current through the monolayer AuNPs is too small to detect. In order to enhance the current signal, an approach with a silver enhancer solution of $\mathrm{AgNO}_{3}$ and hydroquinone was proposed in their study.

In this study, an electrical approach is used to detect DNA hybridization through the establishment of gold nanostructure on the gap surface between two electrodes. The gold nanostructure is established by such a way that employs functional single strand DNA as linking chemical. Electrical detection for DNA hybridization has some advantages over the optical approach in rapid clinical diagnosis of genetic diseases. These advantages include easier operation, less instrumental cost, and denser measuring points. However, the sensitivity and consistency of electrical detection should be improved significantly in order to have practical application.

In this study, we describe the use of bioconjugate that consists of oligonucleotide probes and colloidal AuNPs for DNA hybridization detection via the construction of multilayer nanostructure on top of the bottom layer through a layerby-layer process. Specifically, oligonucleotide probes are conjugated to colloidal AuNPs. They are used to selectively recognize surface-confined target DNA via sequence-specific hybridization with in situ detection. The substrate between the nano-gap electrodes, a chemical compound 3aminopropyltrimethoxysilane (APTMS), is used to modify the substrate surface. One end of the APTMS compound is to silanize the substrate surface while the thiol end of the APTMS compound is used to bind the gold nanoparticles. At high concentration of target DNA, gold nanoparticle multilayer is then established through DNA hybridization among thiol-modified capture, thiol-modified probe, and target DNA single strands. At low concentration of target DNA, it is required to establish a middle layer for enhancing electrical signal through electrodes. A substantial improvement in electrical response is achieved compared with an unamplified detection situation. To further support the validity of this approach, either salt solution or a thermal denaturation process can be used to prove whether DNA hybridization is complementary. 
In addition, this study aims at developing an electrical detection method for DNA hybridization without any amplification of target DNA through a polymerase chain reaction that is usually time consuming. Therefore, the detection sensitivity of this approach must reach $1 \mathrm{fM}$.

\section{Experimental details}

\subsection{Preparation of gold nanoparticles}

In this study, the first step is to prepare dispersed gold nanoparticles in aqueous solution by using a chemical reduction method [16]. In a flask, $80 \mathrm{ml}$ distill water and $1 \mathrm{mg} \mathrm{HAuCl}_{4}$ are mixed, and then it was heated up to $60^{\circ} \mathrm{C}$ with vigorous stirring. An addition of $20 \mathrm{ml}$ water solution with $0.05 \mathrm{mg}$ trisodium citrate and $0.01 \mathrm{mg}$ tannic acid is added into the flask. The color of the solution gradually changes to crimson and then violet around $3 \mathrm{~min}$ after the solution starts to change color. Afterwards, the aqueous solution is heated to boiling for an additional $15 \mathrm{~min}$. After returning to room temperature, colloidal gold nanoparticles are formed in the solution.

The solution of AuNPs is measured by a Hitachi U3310 UV-Vis spectrometer and a highresolution transmission electronic micrograph (HR-TEM, model: H-7000, Hitachi) to determine the size of gold nanoparticles. The HR-TEM micrograph and UV-Vis absorption spectrum of gold nanoparticles are shown in Fig. 1(a) and (b), respectively. The UV-Vis absorption spectrum of AuNPs solution shows a strong surface plasma resonance at a wavelength of $523 \mathrm{~nm}$. From the HR-TEM micrograph of gold nanoparticles, the diameter of monodispersed Au colloidal is found to be in the range of $12 \pm 4 \mathrm{~nm}$. It is worth noting that the size of gold nanoparticles in the solution

(a)
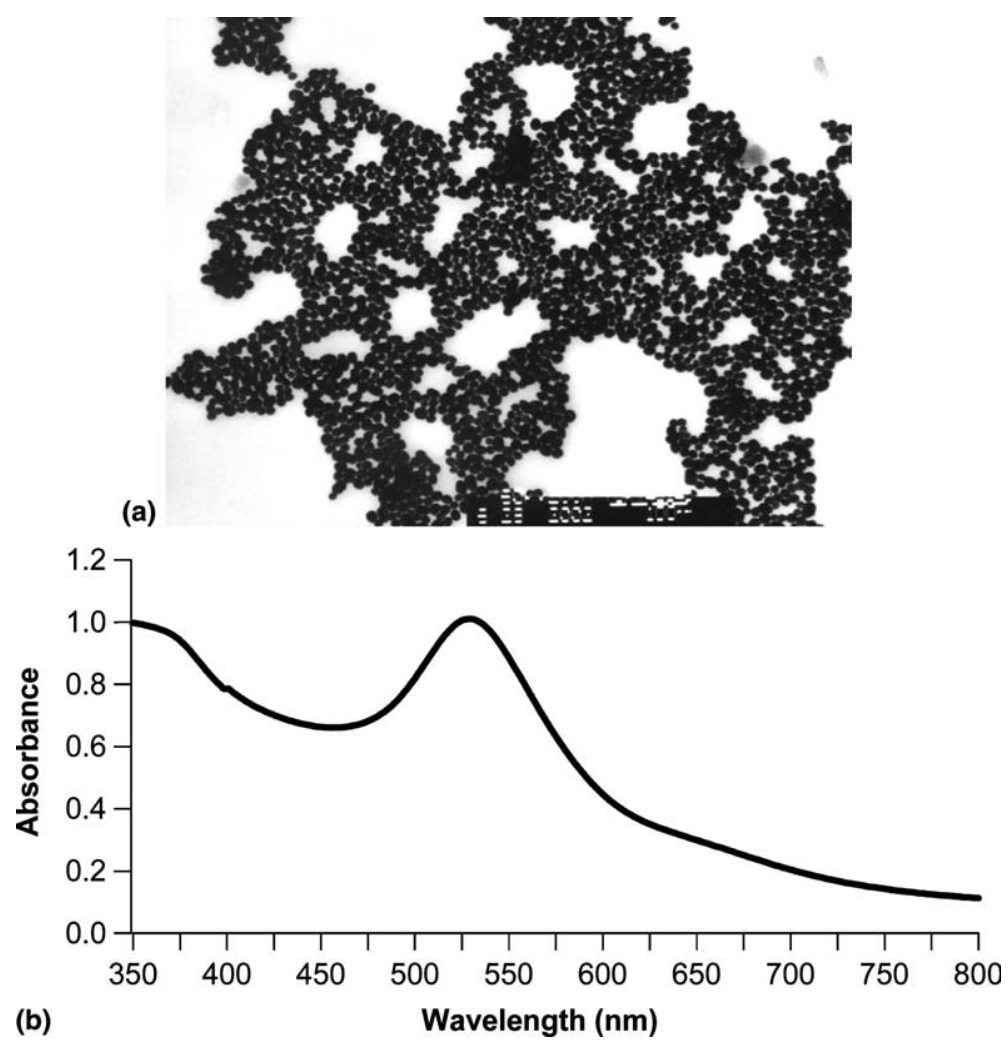

Fig. 1. Measured results of gold nanoparticles with an average diameter of $12 \mathrm{~nm}$ : (a) TEM micrograph; (b) UV-Vis absorption spectrum. 
can be varied by changing the concentration of trisodium citrate in the aqueous solution.

\subsection{The fabrication of nano-gap gold electrodes}

The procedure for fabricating nano-gap electrode is shown in Fig. 2. The procedure for establishing the multilayer structure of gold nanoparticles between electrodes is illustrated in Fig. 3. The first step for manufacturing nano-gap electrode is to sandwich a p-type $\operatorname{Si}(100)$ wafer (phoenix, San Jose, CA) with a $2000 \AA \mathrm{SiO}_{2}$ thin film using PECVD. It is then followed by spin coating of a $7000 \AA$ thick photoresistant on the $\mathrm{SiO}_{2}$ surface. The pattern of electrodes on the photoresistant is obtained by using a direct writing approach with an E-beam writer. After the wafer is exposed to the E-beam writer, it is placed into developed etchant to yield a $300 \mathrm{~nm}$-gap on the photoresistant. The next step is to deposit titanium of $5 \mathrm{~nm}$ thick by using a thermal deposition process. It is then followed by a deposition of $35 \mathrm{~nm}$ gold thin film. The final step is to immerse the silicon wafer in acetone solution for $2 \mathrm{~h}$. The electrodes with 300-600 nm nanogap can be obtained on the silicon wafer.

\subsection{Establishing self-assembly gold nanoparticle monolayer and multilayer}

To clean thoroughly, the substrate is rinsed with water in an ultrasonic cleaner for $5 \mathrm{~min}$. It is then immersed in the $1 \mathrm{mM} 3$-aminopropyltrimethoxysilane (Sigma Chemical Co. St. louis, $\mathrm{MO}$ ) of DMSO solution for at least $2 \mathrm{~h}$ at room temperature, followed by rinsing with DMSO

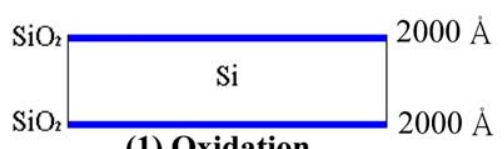

(1) Oxidation

$7000 \AA \mathrm{APR}$

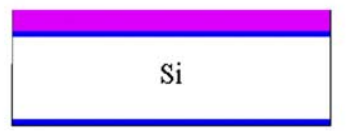

(2) Spin coating

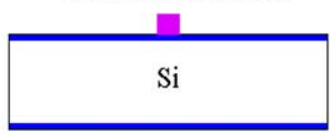

(3) Exposure and development

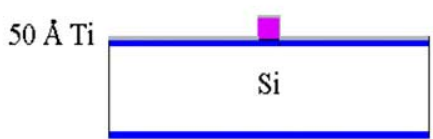

(4) Ti deposition

$350 \AA \mathrm{Au}$

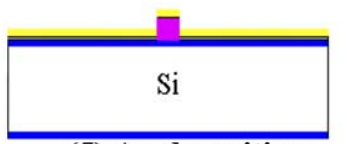

(5) Au deposition

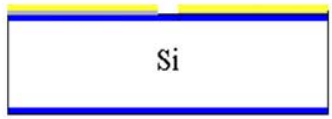

(6) Immersing in acetone
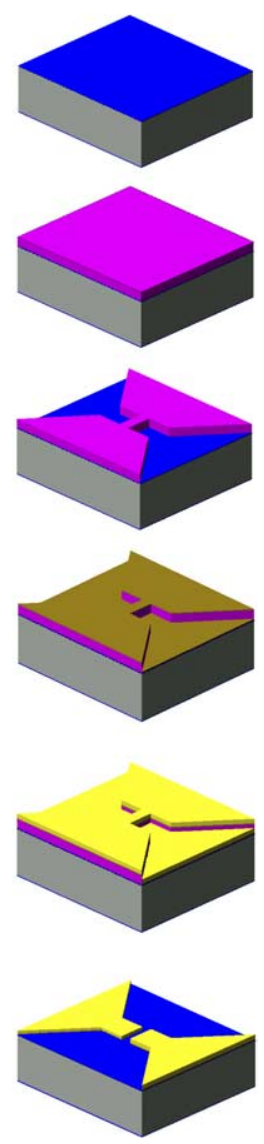

Fig. 2. Fabrication sequence of nano-gap gold electrodes using a lift-off process. 


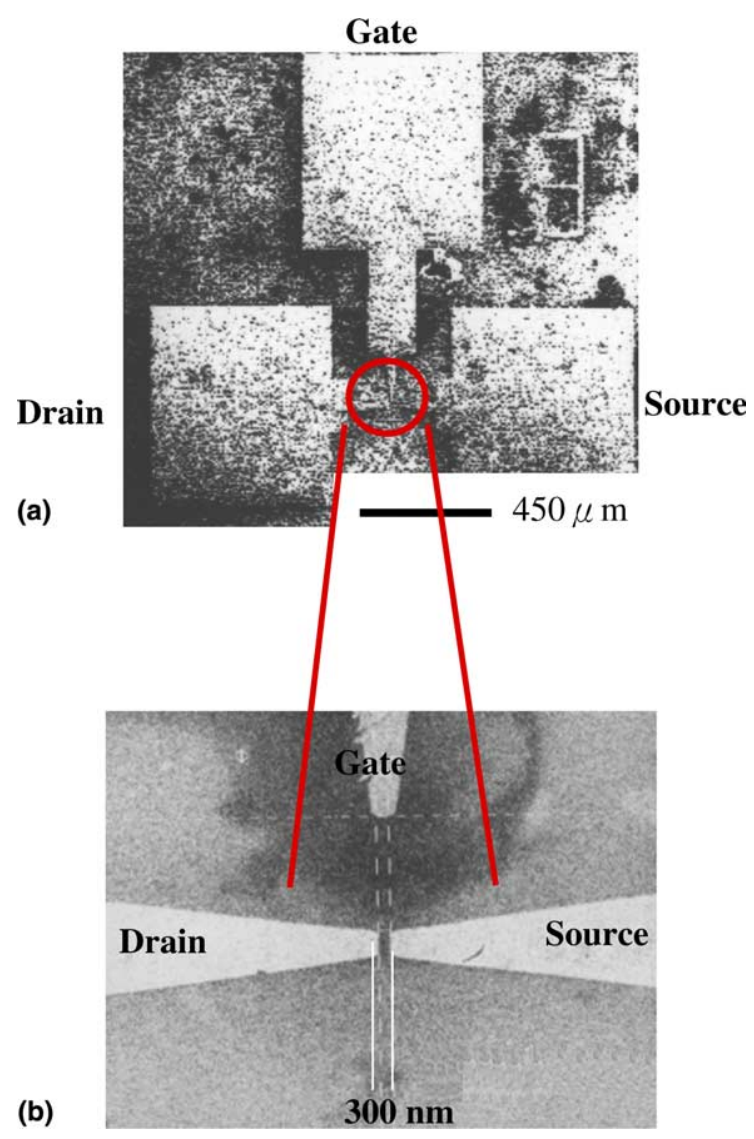

Fig. 3. The SEM images of nano-gap electrode with a magnification of (a) 300, and (b) 4000. The electrodes include gate, drain and source (thickness, $350 \AA$; the distance of gap, $300 \mathrm{~nm})$.

and dried under $\mathrm{N}_{2}$. The functionalized substrate is immersed in the AuNPs solution overnight, then rinsed with distilled water and dried under $\mathrm{N}_{2}$.
The sequences of single strand capture, target, and probe DNAs as well as single base-pair mismatch of target oligonucleotides (cDNA, tDNA, pDNA and single-bp mismatch tDNA) are shown in Fig. 4. The oligonucleotides are prepared according to standard protocols [16].

The procedure to establish double layer of gold nanoparticles can be shown in Fig. 5. Except the middle layers, both bottom and top layers are established by using the same chemical compounds for the different procedures, APTMS for the bottom layer and DNA hybridization for the top layer. The middle layer is formed by using hexanedithiol as a linking chemical compound. It is worth noting that the number of middle layer can be greater than one. APTMS, whose thiol end is bound with gold nanoparticle, modifies silicon oxide substrate surface. To perform the detection of target DNA, cDNA $(100 \mu \mathrm{L}, 1 \mu \mathrm{M})$ is deaerated in $10 \mathrm{mM}$ HEPES (4-(2-hydroxyethyl)1-piperazineethanesulfonic acid, J.T. Baker Chem. Co.), 5 mM EDTA buffer, pH 6.6 (HEPES buffer). The self-assembled gold-particle monolayer substrate is immersed in the cDNA solution for $15 \mathrm{~h}$ at room temperature, followed by rinsing with $50 \mathrm{mM}$ sodium phosphate, $1 \mathrm{M} \mathrm{NaCl}$, pH 6.5 (SPSC buffer) to remove non-covalently bound DNA, and is dried under $\mathrm{N}_{2}$. The substrate is immersed in four different concentrations of tDNA $(0.1 \mu \mathrm{M}, 1 \mathrm{nM}, 10 \mathrm{pM}$ and $1 \mathrm{fM}, 24-\mathrm{mer})$ solution $(100 \mu \mathrm{L})$ and pDNA solution $(12-\mathrm{mer}, 100 \mu \mathrm{L}$, $0.1 \mu \mathrm{M}$ ) for $2 \mathrm{~h}$ to hybridize, followed by immersing in a SPSC buffer to remove excess reagents. The substrate is then immersed in a solution of AuNPs in $0.3 \mathrm{M}$ PBS buffer $(0.3 \mathrm{M} \mathrm{NaCl}$,

captureDNA $3^{\prime}-\mathrm{HS}^{-\mathrm{A}_{10}}{ }^{-\mathrm{CCT}^{-}}$AAT AAC AAT-5'

\begin{tabular}{|c|c|}
\hline probeDNA & 3'-TTA TAA CTA TTC CTA-A $10-\mathrm{SH}-5^{\prime}$ \\
\hline targetDNA & 5'- GGA TTA TTG TTA AAT ATT GAT AAG GAT-3' \\
\hline $\begin{array}{l}\text { single base } \\
\text { pair mismatch } \\
\text { of targetDNA }\end{array}$ & 5'- GGA TTA TCG TTA AAT ATT GAT AAG GAT-3' \\
\hline
\end{tabular}

Fig. 4. The DNA sequences of the capture, target, probe and single base pair mismatch of target oligonucleotide. 


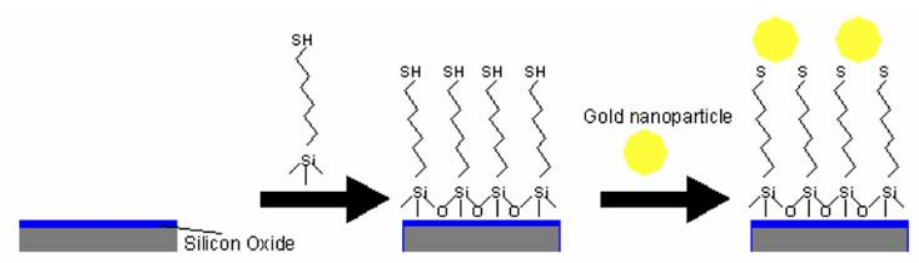

Si substrate

(a)

(b)

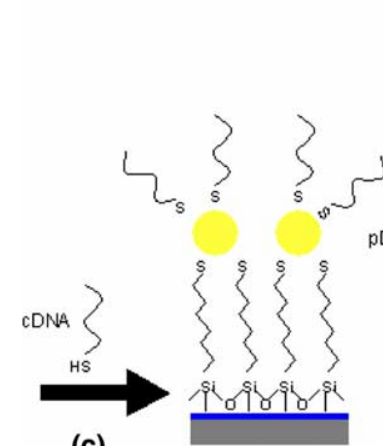

(c)

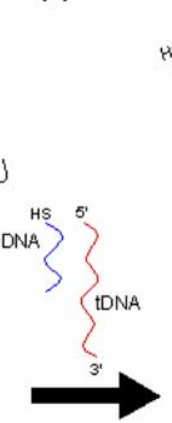

(d)

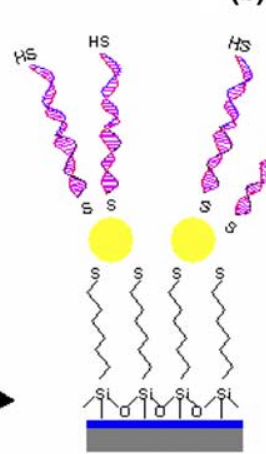

b)
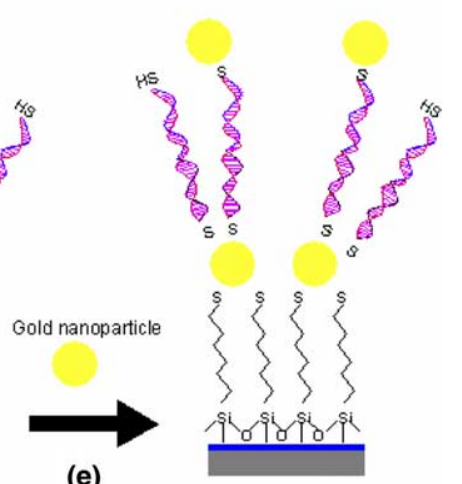

(e)

Fig. 5. Chemistry of the attachment of thiol-modified DNA oligomers to self-assembly AuNPs monolayer. (a) Surface modification with THMS, (b) Addition of AuNPs reacts to the thiol molecule, (c) An alkanethiol-cDNA reacts with AuNPs monolayer, (d) tDNA added and hybridized with cDNA and pDNA, thiol reacts with multilayer AuNPs, (e) The thiol-DNA oligomer subsequently reacts with the AuNPs surface, to yield the self-assembly of multilayer of AuNPs on the below illustration.

$\left.10 \mathrm{mM} \mathrm{NaH}{ }_{2} \mathrm{PO}_{4} / \mathrm{Na}_{2} \mathrm{HPO}_{4}, \mathrm{pH} 7\right)$, followed by washing with the $0.3 \mathrm{M}$ PBS buffer to remove excess AuNPs and is dried under $\mathrm{N}_{2}$. If hybridization among DNAs (pDNA, cDNA/complementary tDNA or single-bp mismatch tDNA) does occur, the top layer of gold nanoparticles is established between nano-gap electrodes. If there is no hybridization, only monolayer of gold nanoparticles is established. However, a higher electric current can be detected through self-assembly multilayer gold nanoparticles if target DNA, probe DNA, and nanoparticles are placed in the solution at the same time. When gold nanoparticles are placed in the solution after the hybridization between target, probe, and capture DNAs, the electric current is not as high. In this study, the latter approach for establishing self-assembly gold nanoparticle mutlilayer is used.

For verifying the specificity of target DNA, it is required to check whether the hybridization among DNAs has any mis-match. To check it, the chip can be washed with a $0.01 \mathrm{M}$ PBS $\left(0.01 \mathrm{M} \mathrm{NaCl}, 10 \mathrm{mM} \mathrm{NaH}{ }_{2} \mathrm{PO}_{4} / \mathrm{Na}_{2} \mathrm{HPO}_{4}, \mathrm{pH}\right.$ 7) buffer at room temperature [16]. If the hybridization among DNAs is not fully complementary, the top layer of gold nanoparticles is washed away. As a result, the electric current is reduced significantly back to a value that is obtained for selfassembly gold nanoparticle monolayer. The $I-V$ curves of self-assembly gold nanoparticle multilayer are measured by a HP 4156A precision semiconductor parameter analyzer. The applied

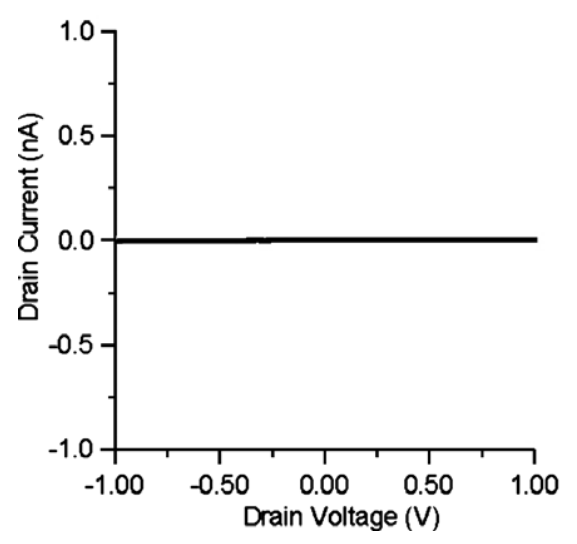

Fig. 6. Current-voltage curve for the monolayer AuNPs at a scan rate of $10 \mathrm{mV} / \mathrm{s}$. 
voltage ranges from -1 to $+1 \mathrm{~V}$ with a scan rate of $1 \mathrm{mV} / \mathrm{s}$.

\section{Results and discussion}

Methods for electrical detection of DNA with AuNPs were previously reported by Tsai and coworkers $[7,8]$. However, the lowest concentration of target DNA detected in their study is $10 \mathrm{pM}$. In this study, the gap distance between electrodes is reduced from $600 \mathrm{~nm}$ in their study to $300 \mathrm{~nm}$. Fig. 3 shows the FE-SEM micrographs of nanogap electrodes. In this study, a field-emission scanning electron microscopy (FE-SEM: JEOL, JSM-6500F) is used to observe the nano-gap electrodes and self-assembly gold nanoparticle multilayer on the surface between electrodes. Once
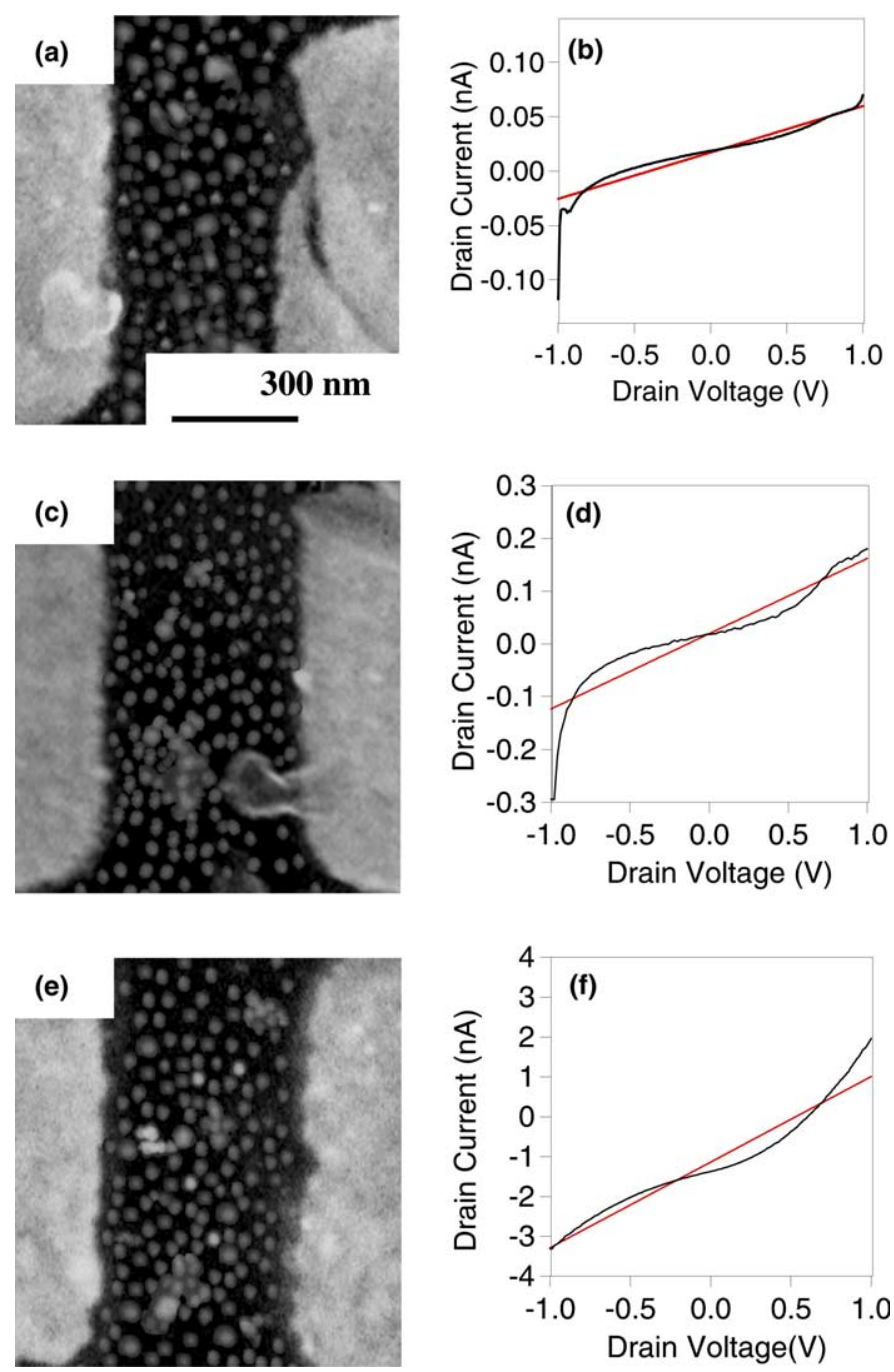

Fig. 7. FE-SEM images of the AuNPs multilayer at different concentrations of target DNA: (a) $1 \mathrm{fM}$, (c) $10 \mathrm{fM}$, and (e) $100 \mathrm{fM}$. Current-voltage curves of the AuNPs multilayer at different concentrations of target DNA: (b) $1 \mathrm{fM}$, (d) $10 \mathrm{fM}$, and (f) $100 \mathrm{fM}$. Here, tDNAs were hybridized to cDNA and pDNA in $0.3 \mathrm{M}$ PBS for $2 \mathrm{~h}$ in all experiments. 
self-assembly gold nanoparticle multilayer is established on the silicon wafer, the color of biochip at measuring spot turns into deep brown.

Current-voltage $(I-V)$ behavior of the device is measured via ohmic contacts as shown in Fig. 6. If there is no AuNPs in the nano gap, the current of the device would be lower than $50 \mathrm{fA}$ as observed. Once the monolayer AuNPs is established on the gap surface between elec- trodes, the current of the monolayer AuNPs is still lower than $1 \mathrm{pA}$. Our precious study [8] employed MPTMS to immobilize gold nanoparticles to establish the monolayer AuNPs on $\mathrm{SiO}_{2}$ surface. Note that the particle density of the monolayer AuNPs increases from $\sim 1230$ particles $/ \mu \mathrm{m}^{2}$ to $\sim 1450$ particles $/ \mu \mathrm{m}^{2}$ if the MPTMS used in the precious study for immobilizing gold nanoparticles is replaced by ATPMS.
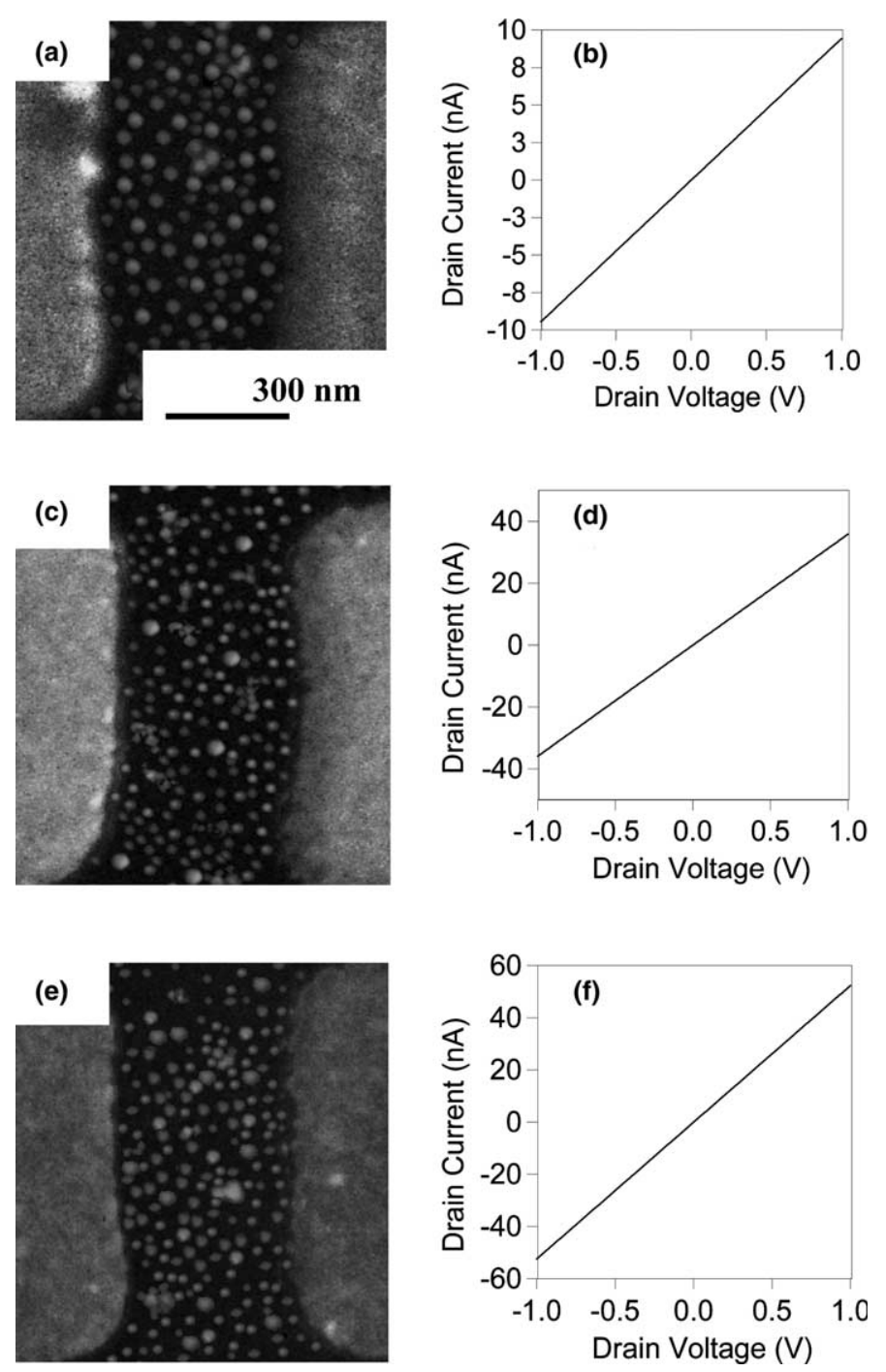

Fig. 8. FE-SEM images of the AuNPs multilayer at different concentrations of target DNA: (a) 1 pM, (c) 10 pM, and (e) 100 pM. Current-voltage curves of the AuNPs multilayer at different concentrations of target DNA: (b) 1 pM, (d) 10 pM and (f) 100 pM. Here, tDNAs were hybridized to cDNA and pDNA in $0.3 \mathrm{M}$ PBS for $2 \mathrm{~h}$ in all experiments. 
Fig. 7 shows the FE-SEM images and the $I-V$ curves of the multilayer AuNPs at different tDNA concentrations of 1,10 and $100 \mathrm{fM}$. Fig. 8 shows the FE-SEM images and the $I-V$ curves of the multilayer AuNPs at different tDNA concentrations of 1, 10 and $100 \mathrm{pM}$. Electrons tunnel more readily through the junction when enough energy is supplied. The linear curve is typical of ohmic devices. Figs. 7 and 8 show the FE-SEM images of the $\mathrm{SiO}_{2}$ surface treated in a manner identical to the treatment of the electrode gaps before and after incorporation of the second AuNPs via DNA immobilization, which clearly indicates that AuNPs density increases with increasing tDNA concentration. Higher tDNA concentration increases the AuNPs density on $\mathrm{SiO}_{2}$ surface. The average densities of the particles are $\sim 1500$, $\sim 1550, \sim 1650, \sim 1900, \sim 2030, \sim 2200$ particles/ $\mu \mathrm{m}^{2}$ as shown in Figs. 7(a), (c), (e) and 8(g), (i), (k). However, in the absence of tDNA and after the chip is washed with a $0.3 \mathrm{M}$ PBS buffer, the same signal as to the monolayer of AuNPs is observed, less than $1 \mathrm{pA}$ with an applied voltage ranging from -1 to $1 \mathrm{~V}$. Using this method, we can target oligonucleotide over a wide concentration range. The right side of Fig. 7 and 8 show the $I-V$ curves of the nano-gap electrode without the silver enhancing approach [16]. Using this method, electrical detection is feasible in the $1 \mathrm{fM}$ to $100 \mathrm{pM}$ concentration range. Fig. 9 shows a dependence of electric resistance of the multilayer AuNPs with the target DNA concentration (M). It can be estimated that the correlation between the target DNA concentration/tDNA/versus resistance/R/of the multilayer AuNPs is

$\log (/ \mathrm{tDNA} /)=-4.0625-1.0375 \cdot \log / R /$.

The difference in conductivity of multilayer with different concentration of tDNA can be readily observed at room temperature. The self-assembly procedure described above provides a versatile and convenient method for DNA detection. The observation of increased AuNP density is consistent with our anticipation for DNA hybridization. The system is based on nano-gap electrodes, it is positioned for massive multiplexing through the use of electronic properties by using different compounds for the assembly of AuNPs multilayer.

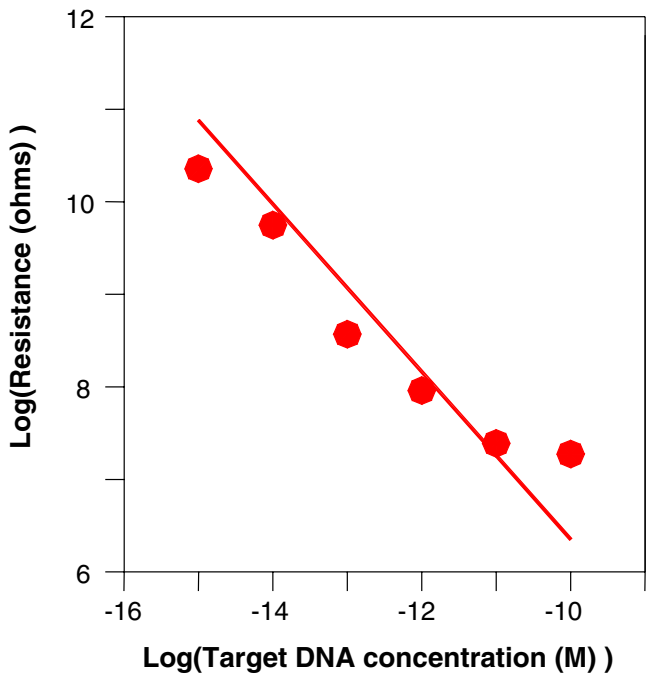

Fig. 9. Measured results of electric resistance of the AuNPs multilayer versus target DNA concentration.

\section{Conclusion}

An electrical detection on DNA hybridization with multilayer gold nanoparticles is described in this paper. The system is based on gold nanoparticles synthesized by a chemical reduction method and a monolayer of the particles established on the surface between electrodes. Significantly, the hybridization within DNA can then be identified from an increase in measured current through electrodes due to additional layers of gold nanoparticles, which are established through hybridization among DNAs. The tDNA concentration affects the measured magnitude of electric current through multilayer gold nanoparticles.

\section{Acknowledgment}

We deeply appreciate the financial support by the Nation Science Council under the Grant number of NSC-92-2212-E-002-050.

\section{References}

[1] M.E. Napier, C.R. Loomis, M.F. Sistare, J. Kim, A.E. Eckhardt, H.H. Thorp, Bioconjugate Chem. 8 (1997) 906. 
[2] S.O. Kelly, E.M. Boon, J.K. Barton, N.M. Jackson, M.G. Hill, Nucleic Acids Res. 27 (1999) 4830.

[3] C.J. Yu, Y. Wan, H. Yowanto, J. Li, C. Tao, M.D. James, C.L. Tan, G.F. Blackburn, T.J. Meade, J. Am. Chem. Soc. 123 (2001) 11155.

[4] L. He, M.D. Musick, S.R. Nicewarner, F.G. Salinas, S.J. Benkovic, M.J. Natan, C.D. Keating, J. Am. Chem. Soc. 122 (2000) 9071.

[5] W.C.W. Chan, S. Nie, Science 281 (1998) 2016.

[6] S.R. Nicewarner-Peńa, R.G. Freeman, B.D. Reiss, L. He, D.J. Pena, I.D. Walton, R. Cromer, C.D. Keating, M.J. Natan, Science 294 (2001) 137.

[7] C.C. Chen, C.Y. Tsai, F.H. Ko, C.C. Pun, H.L. Chen, P.H. Chen, Jap. J. Appl. Phys. 43 (6A) (2004) 3611.

[8] C.Y. Tsai, Y.H. Tsai, C.C. Pun, B. Chan, T.Y. Luh, C.C. Chen, F.H. Ko, P.J. Chen, P.H. Chen, Microsyst. Technol. 11 (2005) 91.
[9] P.H. Chen, C.Y. Tsai, Y.H. Tsai, C.C. Chen, F.H. Ko, Symp. Nano Device Tech. A 5 (5) (2003).

[10] M. Hayat (Ed.), Colloidal Au: Principles, Methods and Applications, vol. 1, Academic Press, San Diego, 1989.

[11] P.E. Buckle, R.J. Davies, T. Kinning, D. Yeung, P.R. Edwards, D. Pollard-Knight, C.R. Lowe, Biosens. Bioelectron. 8 (1993) 355.

[12] K. Choi, H.J. Youn, Y.C. Ha, K.J. Kim, J.D. Choi, J. Microbiol. 36 (1998) 43.

[13] L.A. Lyon, M.D. Musick, M.J. Natan, Anal. Chem. 70 (1998) 5177.

[14] L.A. Lyon, M.D. Musick, P.C. Smith, B.D. Reiss, D.J. Penã, M.J. Natan, Sensor. Actuator. B 54 (1999) 118.

[15] L.A. Lyon, D.J. Penã, M.J. Natan, J. Phys. Chem. B 103 (1999) 5826.

[16] S.J. Park, T.A. Taton, C.A. Mirkin, Science 295 (22) (2002) 1503. 